\title{
BACILLUS EM DIETAS PARA ALEVINOS DE TILÁPIA DO NILO, VARIEDADE GIFT
}

\author{
BACILLUS IN DIETS FOR FINGERLINGS OF NILE TILAPIA, GIFT VARIETY
}

\author{
Daniele Menezes ALBUQUERQUE'; Nilton Garcia MARENGONI²; \\ Ilson MAHL; ${ }^{3}$ Milton César de MOURA ${ }^{4}$; \\ Maria Del Pilar RODRIGUEZ-RODRIGUEZ ${ }^{5}$; Juliana Minardi GALO ${ }^{6}$; \\ Ricardo Pereira RIBEIRO ${ }^{7}$
}

\begin{abstract}
1. Docente do Curso de Engenharia de Aquicultura, Faculdade de Ciências Agrárias - FCA, Universidade Federal da Grande Dourados UFGD, Dourados, MS, Brasil. danielemenezes2003@yahoo.com.br; 2. Docente do Curso de Zootecnia, Universidade Estadual do Oeste do Paraná - UNIOESTE, Centro de Ciências Agrárias - CCA, Marechal Cândido Rondon, PR, Brasil; 3. Engenheiro de Pesca, Copacol, Nova Aurora, PR, Brasil; 4. Mestre em Recursos Pesqueiros e Engenharia de Pesca, Centro de Ciências Exatas - CCE - UNIOESTE, Toledo, PR, Brasil; 5. Doutora em Zootecnia, Universidade Estadual de Maringá - UEM, Maringá, PR, Brasil. 6. Docente do Curso de Zootecnia, Instituto Federal de Educação, Ciência e Tecnologia de Rondônia - IFRO, Ariquemes, RO, Brasil. 7. Docente do Curso de Zootecnia, Centro de Ciências Agrárias - CCA, Universidade Estadual de Maringá - UEM, Maringá, PR, Brasil.
\end{abstract}

RESUMO: Os probióticos vêm se destacando na produção aquícola como promotores de crescimento, especialmente na tilapicultura, por serem capazes de sobreviver ao trato gastrointestinal, aderir células da parede intestinal, reduzir ou prevenir patógenos, não ser patogênico ao hospedeiro. Objetivou-se avaliar o desempenho produtivo, índices corpóreos, macro micronutrientes e composição química da carcaça de alevinos de tilápia do Nilo, variedade GIFT, alimentadas com ração formulada com probióticos Bacillus cereus var. Toyoi e Bacillus subtilis C-3102, durante alevinagem. Foram utilizados 720 pós-larvas com peso médio inicial de 26,6 $\pm 3,4 \mathrm{mg}$. Os peixes foram distribuídos aleatoriamente em um sistema de 24 aquários de $0,03 \mathrm{~m}^{3}$ num delineamento inteiramente casualizado composto por três tratamentos e oito repetições, constituído por dois probióticos e, tratamento ausente de probiótico. Os dados dos parâmetros analisados foram submetidos à ANOVA a 5\%. Não houve diferenças significativas $(p>0,05)$ ao final do cultivo para os parâmetros de peso final, ganho em peso, crescimento específico e consumo de ração. A biomassa final, ganho em biomassa e sobrevivência dos peixes foi afetada significativamente $(p<0,05)$ pela adição de $B$. cereus ou $B$. subtilis em relação ao ausente. Não houve diferenças $(p>0,05)$ nos índices corporais e composição centesimal com probióticos ou ausentes nas rações. A inclusão de quaisquer dos probióticos influenciou $(p<0,05)$ sobre valores de cálcio na carcaça dos alevinos em relação aos peixes ausentes de probióticos. A utilização de B. subtilis ou B. cereus melhora o desempenho produtivo e não afetam negativamente os índices corpóreos, macro e micronutrientes na carcaça de alevinos de tilápia do Nilo, variedade GIFT.

PALAVRAS-CHAVE: Alevinagem. Desempenho Produtivo. Índices Corpóreos. Probióticos. Tilapicultura.

\section{INTRODUÇÃO}

A tilapicultura nas diversas modalidades de sistema de cultivo fomenta a produção aquícola nacional brasileira em torno de 169.306,0 t (BRASIL/IBGE 2014). Para que a produção nacional consiga a cada dia números mais expressivos e alcançar o patamar de maior produtor de pescados mundial é necessário aumentar o volume de pescados cultivados. Em sistemas intensivos de uma forma geral, as densidades de estocagens são altas e a ração é a única fonte de alimento dos peixes, portanto, é essencial a utilização de rações balanceadas e com ingredientes com alto valor biológico e nutrientes digestíveis (CYRINO et al., 2010).

O estresse ocasionado pelo adensamento dos animais, uma má alimentação e fatores abióticos podem influenciar na produção, resultando em peixes com baixa imunidade, sendo assim, o início do desencadeamento de patógenos, ocasionando mortalidades no cultivo (CYRINO et al., 2010). Tendo em vista a necessidade de minimizar o lançamento de efluentes oriundos dos cultivos de peixes e a preocupação em se produzir alimentos de forma sustentavelmente econômica, ambiental e social, faz-se necessário mais estudos no sentindo de desenvolver biotecnologias adequadas para garantir resultados que melhorem a conversão alimentar, menor quantidade de resíduos e um menor custo ao produtor (SAHU, 2008).

A FAO/WHO (2002) definem probióticos como micro-organismos vivos que, administrados em doses adequadas geram benefícios ao animal hospedeiro. Diversos trabalhos envolvendo organismos aquáticos (EL-HAROUN et al., 2006; MARENGONI et al., 2010) relatam a eficiência destes micro-organismos como uma alternativa frente a medicamentos em cultivos. A utilização de bactérias em organismos aquáticos influência o 
meio externo e os prováveis patógenos sobre animal cultivado, devido ao constante contato através dos processos de osmorregulação e alimentação (NAYAK, 2010). Deve-se considerar que alguns probióticos desempenham ações não somente no animal, mas também conjuntamente com o meio em que o organismo é cultivado (KESARCODIWATSON et al., 2008).

Conforme Balcázar et al. (2006) os probióticos são comercializados na forma liofilizada ou líquida, e podem ser ministrados pulverizados nas dietas, adicionados à água de cultivo ou em alimentos vivos. Os probióticos também podem ser administrados com uma única espécie de bactéria, ou em adição a outras espécies ou até mesmo outros gêneros (TIMMERMAN et al., 2004).

Williams et al. (2009) reportam que Bacillus cereus são bactérias gram positivas da família Bacillaceae formadora de esporos, anaeróbias facultativas com largas células vegetativas que podem crescer em temperaturas entre $8-55^{\circ} \mathrm{C}$, porém seu crescimento ótimo ocorre em condições entre $28-35^{\circ} \mathrm{C}$, nos quais seus esporos podem ser isolados de solos, água e vegetais sendo ainda encontrado na flora intestinal de animais. Bacillus subtilis C-3102 são bactérias esporuladas comercial da empresa Calsporin ${ }^{\circledR}$ com aplicação em dietas para animais aquáticos e terrestres (HE et al., 2013).

Desta forma, este estudo teve por objetivos avaliar o desempenho produtivo, índices corpóreos e composição de macro e micronutrientes de alevinos de tilápia do Nilo, variedade GIFT, alimentadas com rações formuladas sob inclusão dos probióticos Bacillus cereus var. Toyoi e Bacillus subtilis C3102.

\section{MATERIAL E MÉTODOS}

O experimento foi conduzido durante 113 dias. Foram utilizadas 720 pós-larvas com peso médio inicial de $26,6 \pm 3,4 \mathrm{mg}$. Os peixes foram distribuídos aleatoriamente em 24 aquários em delineamento inteiramente casualizado composto por três tratamentos e oito repetições, constituído por dois probióticos e um tratamento ausente. Considerou-se uma unidade experimental um aquário com volume útil de $0,03 \mathrm{~m}^{3}$ contendo 30 pós-larvas.

Utilizaram-se dois produtos comerciais como promotores de crescimento, um probiótico contendo Bacillus subtilis C-3102 e o outro Bacillus cereus var. Toyoi (Tabela 1).

As rações foram confeccionadas utilizando a metodologia adaptada de Pezzato et al. (2002). Nas rações que continham na fórmula probiótico, acrescentou-se $1 \%$ do produto no momento da mistura dos ingredientes referente aos estudos sugeridos por ALBUQUERQUE (2011).

Ao final do experimento foram analisados os dados de desempenho produtivo de peso final, ganho em peso, conversão alimentar aparente, crescimento específico e sobrevivência. Semanalmente foram monitorados as variáveis dos parâmetros de qualidade de água oxigênio dissolvido e temperatura utilizando oxímetro digital modelos YSI 550A com auxílio de potenciômetros modelo HI 8314 e condutividade HI 9033 da marca Hanna Instruments ${ }^{\circledR}$, respectivamente.

Tabela 1. Composição percentual e química das rações experimentais para alevinos de tilápia do Nilo cultivados durante a fase de reversão sexual e alevinagem.

\begin{tabular}{lccc}
\hline \multirow{2}{*}{ Ingrediente } & \multicolumn{3}{c}{ Dieta } \\
\cline { 2 - 4 } & Ausente & Bacillus subtilis & Bacillus cereus \\
\hline Farelo de soja & 44,91 & 44,25 & 44,25 \\
Farinha de peixe & 24,50 & 24,65 & 24,65 \\
Farelo de milho & 24,13 & 23,07 & 23,07 \\
Probiótico & - & 1,00 & 1,00 \\
Premix MV & $1(1)$ & 1,00 & 1,00 \\
DL-metionina & 0,21 & 0,21 & 0,21 \\
Antioxidante & 0,02 & 0,02 & 0,02 \\
Óleo de soja & 3,71 & 4,28 & 4,28 \\
Fosfato bicálcico & 2,12 & 2,13 & 2,13 \\
Calcário calcítico & - & 0,01 & 0,01 \\
Sal & 0,30 & 0,30 & 0,30 \\
\hline Total & 100 & 100 & 100 \\
\hline Nutriente & \multicolumn{2}{c}{$(\%)$} \\
\hline Amido & 15,04 & 16,29 & 16,29
\end{tabular}


Cálcio

Energia digestível (tilápia)

Fibra bruta

Fósforo total

Gordura

Lisina total

Metionina total

Proteína bruta

1,55
3296,00
3,22
1,11
6,565
2,35
0,87
37,53

1,55

1,44

3272,00

2,96

1,00

5,92

2,39

1,05

37,24
1,44

3272,00

2,96

1,00

5,92

2,39

1,05

37,24

${ }^{(1)}$ Premix mineral vitamínico: Composição por kg de produto: ferro=10,312 mg; manganês=6,875 mg; cobre=1,100 mg; zinco=16,500 $\mathrm{mg}$; iodo=137 mg; cobalto=82,50 mg; selênio $=124,00 \mathrm{mg}$; cromo=68,75 mg; vit. $A=1.100,000 \mathrm{UI}$; vit. $\mathrm{D}_{3}=344,000 \mathrm{UI} ;$ vit. $\mathrm{E}=27,500$ $\mathrm{mg}$; vit. $\mathrm{K}=1,375 \mathrm{mg}$; vit. $\mathrm{C}=41,250 \mathrm{mg}$; biotina $=130,50 \mathrm{mg}$; colina $=75,625 \mathrm{mg}$; vit. $\mathrm{B}_{9}=825,00 \mathrm{mg}$; inositol=27,500 $\mathrm{mg}$; niacina $=13,750 \mathrm{mg}$; vit. $B_{5}=6,875 \mathrm{mg}$; vit. $B_{6}=2,063 \mathrm{mg}$; vit. $B_{2}=2,750 \mathrm{mg}$; vit. $B_{1}=2,750 \mathrm{mg}$ e vit. $B_{12}=4,120 \mathrm{mg}$.

Os pesos das vísceras, da gordura visceral e do fígado foram obtidos após a retirada das vísceras para determinação dos índices viscerossomático, hepatossomático e de gordura visceral, respectivamente, por meio das equações definidas por Vazoller (1996), 1) IVS = PVS/PV x (100) em que: $\mathrm{IVS}=$ índice viscerossomático $(\%)$; PVS = peso da víscera $(\mathrm{g}) ; \mathrm{PV}=$ peso vivo $(\mathrm{g}) ; 2) \mathrm{IHS}=$ $\mathrm{PF} / \mathrm{PV} \mathrm{x}(100)$ em que: IHS $=$ índice hepatossomático; $\mathrm{PF}=$ peso do fígado $(\mathrm{g}) ; \mathrm{PV}=$ peso vivo (g); e 3) IGV = PGV/PV x (100) em que: $\mathrm{IGV}=$ índice de gordura visceral $(\%) ; \mathrm{PGV}=$ peso da gordura visceral $(\mathrm{g}) ; \mathrm{PV}=$ peso vivo $(\mathrm{g})$.

Após a secagem das amostras das carcaças dos peixes em estufa de circulação de ar forçada a $55^{\circ} \mathrm{C}$ por $48 \mathrm{~h}$ foram moídas e encaminhadas à análise química no Laboratório de Química Ambiental e Instrumental da Unioeste, Campus de Marechal Cândido Rondon-PR. Foram mensurados os teores totais de potássio $(\mathrm{K})$, cálcio $(\mathrm{Ca})$, magnésio $(\mathrm{Mg})$, cobre $(\mathrm{Cu})$, ferro $(\mathrm{Fe})$, manganês $(\mathrm{Mn})$ e zinco $(\mathrm{Zn})$ e dos metais pesados cádmio $(\mathrm{Cd})$, cromo $(\mathrm{Cr})$ e chumbo $(\mathrm{Pb})$ por meio da digestão nitro perclórica (AOAC, 2005) das amostras e determinação por espectrometria de absorção atômica (WELZ; SPERLING, 1999), utilizando o equipamento da marca GBC, modelo 932AA. O teor de fósforo total (P) foi obtido pelo método ultravioleta visível (UV-Vis). O nitrogênio total $(\mathrm{N})$ foi quantificado por digestão sulfúrica de acordo com o método Kjeldahl (TEDESCO et al., 1995).

Os dados de desempenho produtivo, índices corpóreos, macros e micronutrientes, que atenderam os pressupostos de normalidade e homogeneidade a $5 \%$ dos resíduos, pelos testes de Shapiro-Wilk e Levene foram submetidos à ANOVA seguido por Tukey a 5\%, utilizando o software STATISTICA ${ }^{\circledR}$ 7.0. Definiu a componente sistemática: Yjk $=\mu+\alpha j+\varepsilon j k$; No qual: Yjk=Espécie de probiótico j e repetição $k(j=1,2 ; k=1,2,3,4,5,6,7,8) ; \mu$ :
Média populacional; $\alpha \mathrm{j}$ : Efeito do probiótico j; $\varepsilon j \mathrm{k}$ : Erro residual.

Os procedimentos utilizados neste trabalho foram aprovados pela Comissão de Ética na Experimentação Animal e Aulas Práticas da Universidade Estadual do Oeste do Paraná com número de protocolo 80/09.

\section{RESULTADOS E DISCUSSÃO}

As médias e desvios padrões para temperatura nos períodos matutino e vespertino foram respectivamente de $22,59 \pm 1,35^{\circ} \mathrm{C}$ e $22,62 \pm$ $1,43^{\circ} \mathrm{C}$. Durante o período da manhã foram registradas temperatura mínima e máxima de 19 e $25^{\circ} \mathrm{C}$, enquanto que no período da tarde foram de 18,50 e $26^{\circ} \mathrm{C}$. Resultados semelhantes para essa variável foram observados por Marques et al. (2003) estudando níveis de arraçoamento diário para tilápia do Nilo cultivados em temperaturas baixas, concluindo que numa temperatura média de $23^{\circ} \mathrm{C}$ o melhor nível de arraçoamento para esta espécie é de 11,55\% do peso vivo.

Ao final da fase de alevinagem, observou-se que não houve diferenças significativas $(p>0,05)$ nos peixes dos tratamentos que continham probióticos ou não, para os parâmetros de desempenho peso final, ganho em peso, crescimento específico e consumo de ração (Tabela 2).

Embora os valores de desempenho produtivo dos peixes do experimento não tenham revelados diferenças significativas $(p<0,05)$, podese observar na Tabela 2 que o peso individual final dos peixes que variou entre $9,23 \mathrm{~g}$ para o tratamento com adição de Bacillus subtilis e $8,74 \mathrm{~g}$ no tratamento de Bacillus cereus estão em conformidade com os estudos realizados por Farias et al. (2001) que trabalhando com desempenho produtivo da tilápia do Nilo, variedade tailandesa, em tanques obtiveram peixes com pesos individuais finais variando entre 7,47 e 10,18 g. 
Pode-se atribuir este decréscimo de peso, provavelmente as baixas temperaturas registradas durante esta última fase de cultivo, fator este, limitante ao crescimento dos peixes e que segundo El-Sayed e Kawana (2008) sugerem uma temperatura ótima de $28^{\circ} \mathrm{C}$. Moura et al. (2007), avaliando o desempenho e atividade de amilase em tilápia do Nilo ratificou que a temperatura da água influencia o metabolismo e consequentemente no consumo de ração e desempenho produtivo dos animais.

Tabela 2. Valores médios e desvio padrão dos parâmetros de desempenho produtivo observados no cultivo de alevinos de tilápia do Nilo, alimentados com diferentes probióticos durante a fase de alevinagem.

\begin{tabular}{|c|c|c|c|c|}
\hline \multirow{2}{*}{ Parâmetros } & \multicolumn{3}{|c|}{ Dieta } & \multirow{2}{*}{$(F ; p)^{6}$} \\
\hline & Ausente & Bacillus subtilis & Bacillus cereus & \\
\hline Peso final $(\mathrm{g})$ & $8,81 \pm 0,48$ & $9,23 \pm 0,64$ & $8,74 \pm 0,48$ & 0,$24 ; 0,78790$ \\
\hline Ganho em peso (g) & $10,09 \pm 0,48$ & $10,66 \pm 0,64$ & $10,05 \pm 0,48$ & 0,$28 ; 0,75576$ \\
\hline $\operatorname{GPMD}(\mathrm{g} / \mathrm{dia})^{1}$ & $0,11 \pm 0,01$ & $0,12 \pm 0,01$ & $0,11 \pm 0,01$ & 0,$28 ; 0,75576$ \\
\hline $\mathrm{CE}(\% / \mathrm{dia})^{2}$ & $4,58 \pm 0,07$ & $4,85 \pm 0,10$ & $4,59 \pm 0,08$ & 3,$02 ; 0,07060$ \\
\hline Biomassa final (g) & $163,95 \pm 25,96$ & $249,46 \pm 21,23$ & $229,80 \pm 13,90$ & 4,$57 ; 0,02257$ \\
\hline Ganho em biomassa (g) & $158,30 \pm 25,85$ & $242,58 \pm 21,27$ & $220,41 \pm 13,78$ & 4,$70 ; 0,02060$ \\
\hline Consumo de ração (g) & $191,32 \pm 23,70$ & $239,85 \pm 17,73$ & $242,57 \pm 10,52$ & 2,$53 ; 0,10381$ \\
\hline Conversão alimentar & $1,63 \pm 0,41$ & $1,02 \pm 0,06$ & $1,11 \pm 0,05$ & 1,$87 ; 0,17855$ \\
\hline Sobrevivência (\%) & $76,43 \pm 0,08 b$ & $94,58 \pm 0,01 \mathrm{a}$ & $93,76 \pm 0,02 \mathrm{a}$ & 5,$46 ; 0,01233$ \\
\hline $\operatorname{IHS}(\%)^{3}$ & $0,20 \pm 0,04$ & $0,18 \pm 0,02$ & $0,19 \pm 0,02$ & 0,$18 ; 0,835$ \\
\hline $\operatorname{IVS}(\%)^{4}$ & $1,29 \pm 0,09$ & $1,14 \pm 0,08$ & $1,24 \pm 0,06$ & 1,$09 ; 0,353$ \\
\hline $\operatorname{IGV}(\%)^{5}$ & $0,10 \pm 0,02$ & $0,19 \pm 0,12$ & $0,06 \pm 0,01$ & 0,$82 ; 0,454$ \\
\hline
\end{tabular}

A biomassa final, ganho de biomassa e sobrevivência dos peixes foram afetada significativamente $(p<0,05)$ pela adição de qualquer um dos probióticos em relação ao ausente (Tabela 2). Aly et al. (2008) estudando o efeito de probióticos na sobrevivência, crescimento e submetendo tilápia do Nilo a infecção, observaram sobrevivências mínimas de $68,88 \%$ e máximas de $84,17 \%$, para os grupos ausentes de probióticos e o probiótico Organic Green ${ }^{\circledR}$, respectivamente. Os autores relatam que o gênero Bacillus demonstra um ótimo potencial para efeitos imunoestimulantes.

Durante o período de 45 dias de cultivo a sobrevivência dos alevinos em todos os grupos experimentais manteve-se acima de 96\%. Os probióticos começaram a atuar na sobrevivência após a quarta biometria, sendo os peixes que não se alimentaram de probióticos resultaram em uma perda de $25,5 \%$. Paralelamente, os peixes alimentados com qualquer um dos probióticos permaneceram com sobrevivências acima de 90\% (Tabela 2).

Observa-se na Tabela 2, que não houve diferenças significativas $(p>0,05)$ entre os índices corporais dos peixes dos tratamentos contendo probióticos ou ausentes, durante $\mathrm{o}$ final do experimento. Similarmente ao que foi observado por Abd-El-Rhman (2009), que avaliou o efeito da própolis sob a bactéria Aeromona hydrophila em alevinos de tilápia do Nilo, também não encontrou diferenças $(p>0,05)$ para o índice hepatossomático. Provavelmente, as células do fígado não sofram nenhuma influência da ação de probióticos no organismo dos peixes por conta da baixa concentração na qual foi inclusa o probiótico na alimentação.

Na Tabela 3, estão expressos os valores médios e desvio padrão de composição centesimal dos alevinos de tilápia do Nilo ao final do experimento. Para as variáveis de proteína bruta, extrato etéreo, umidade e matéria mineral e matéria seca não se observaram diferenças $(p>0,05)$ entre os peixes alimentados com dietas contendo ou não probióticos.

Os resultados encontrados neste trabalho foram inferiores aos observados por Hisano et al. (2007) alimentando alevinos de tilápia do Nilo com leveduras íntegra, autolisada e parede celular, e que também não constataram diferenças na composição centesimal dos alevinos. El-Haroun et al. (2006) utilizando o probiótico Biogen ${ }^{\circledR}$ em dietas para promover o crescimento de tilápia do Nilo, 
observaram para os parâmetros de umidade, proteína bruta, lipídeos e cinzas valores médios mínimos e máximos de 71,13 e 75,49; 13,50 e 15,$33 ; 4,22$ e 8,$29 ; 5,26$ e 6,73 , respectivamente. Essas diferenças devem-se a formulação elaborada no presente experimento que se utilizou de uma dieta isoprotéica e isocalórica, contendo 38\% de PB e $3272 \mathrm{kcal} \mathrm{kg}^{-1}$. Ogawa (1999) relatou que o músculo do pescado pode conter entre 60 e $85 \%$ de umidade, $20 \%$ de proteína em média, 1 a $2 \%$ de cinzas, 0,3 a $1 \%$ de carboidrato e de 0,6 a $36 \%$ de lipídeos.

Tabela 3. Valores médios e desvio padrão da composição centesimal (\%) na matéria seca da carcaça de alevinos de tilápia do Nilo alimentados com diferentes probióticos.

\begin{tabular}{lcccc}
\hline \multirow{2}{*}{\multicolumn{1}{c}{ Nutriente $(\%)$}} & \multicolumn{3}{c}{ Dieta } & \multirow{2}{*}{$(\mathrm{F} ; \mathrm{P})^{(1)}$} \\
\cline { 2 - 4 } & Ausente & Bacillus subtilis & Bacillus cereus & \\
\hline Proteína Bruta & $15,41 \pm 0,35$ & $15,80 \pm 1,90$ & $15,09 \pm 0,37$ & 0,$10 ; 0,90696$ \\
Matéria Mineral & $3,94 \pm 0,59$ & $4,55 \pm 0,38$ & $4,48 \pm 0,11$ & 0,$67 ; 0,52476$ \\
Extrato Etéreo & $8,77 \pm 0,25$ & $8,32 \pm 0,80$ & $7,43 \pm 0,87$ & 0,$95 ; 0,40216$ \\
Matéria Seca & $23,03 \pm 0,29$ & $24,42 \pm 2,20$ & $24,40 \pm 0,59$ & 0,$36 ; 0,69988$ \\
\hline
\end{tabular}

${ }^{(1)} \mathrm{F}$ : Variável do teste, $\mathrm{P}$ : valores críticos

$\mathrm{Na}$ Tabela 4, pode-se observar que não houve efeito $(p>0,05)$ da inclusão de probióticos sobre a carcaça de alevinos de tilápia em relação aos teores de nitrogênio $(\mathrm{N})$, potássio $(\mathrm{K})$ e magnésio $(\mathrm{Mg})$. A inclusão de quaisquer dos probióticos influenciou $(p<0,05)$ nos teores de Ca na carcaça de alevinos de tilápia do Nilo em relação aos peixes ausentes de probióticos. Este macro mineral possui a maior participação na estrutura óssea dos peixes podendo ser depositado nas escamas ou participar dos processos metabólitos das células e ativação de enzimas, contrações musculares, integridade da membrana celular e transmissão nervosa (LALL, 2002). O cálcio pode ser absorvido diretamente da água quando satisfaz a exigência total através dos processos osmorregulatórios ou disponibilizados por suplementação dietética. Existem várias interrelações do cálcio com outros micro minerais, podendo influenciar na absorção, biodisponibilidade por meio de uma competição enzimática, ou substituição de um sítio de ligação (LALL, 2002).

Levando em consideração que vários estudos comprovam o aumento da vilosidade intestinal utilizando probióticos (Mello et al., 2013; Tachibana et al., 2012) e, portanto estimulam uma melhor absorção de macro e micro minerais. É importante salientar, diante dessas informações que pode-se utilizar o objetivo da inclusão de probióticos como alternativa de reposição de íons em situações em que o animal sofre um estresse a exemplo de adensamento das unidades de cultivo, manejo incorreto, qualidade da água inadequada, os peixes podem perder íons através das brânquias. $\mathrm{O}$ cálcio é um nutriente importante para reduzir estas perdas e como verificamos nas dietas que continham probióticos em sua formulação, os peixes absorveram melhor este nutriente que se deve provavelmente a uma melhor resposta frente à absorção nos sítios de ligação.

Tabela 4. Valores médios e desvio padrão de macro nutrientes $(\mathrm{g} / \mathrm{kg})$ e micronutrientes $(\mathrm{mg} / \mathrm{kg})$ da carcaça de alevinos de tilápia do Nilo alimentados com diferentes probióticos.

\begin{tabular}{lcccc}
\hline \multirow{2}{*}{ Macronutriente } & \multicolumn{3}{c}{ Dieta } & \multirow{2}{*}{$(\mathrm{F} ; \mathrm{p})^{(1)}$} \\
\cline { 2 - 4 } & Ausente & Bacillus subtilis & Bacillus cereus $_{n}$ & 0,$03 ; 0,96851$ \\
Nitrogênio (N) & $96,48 \pm 2,34$ & $95,74 \pm 3,75$ & $96,76 \pm 2,53$ & 0,$98 ; 0,39367$ \\
Potássio (K) & $7,66 \pm 0,13$ & $7,40 \pm 0,11$ & $7,56 \pm 0,15$ & 7,$04 ; 0,00458$ \\
Cálcio (Ca) & $53,31 \pm 1,68 \mathrm{~b}$ & $62,93 \pm 2,14 \mathrm{a}$ & $60,76 \pm 1,85 \mathrm{a}$ & 0,$04 ; 0,96114$ \\
Magnésio (Mg) & $2,69 \pm 0,10$ & $2,66 \pm 0,15$ & $2,72 \pm 0,17$ & 0,$94 ; 0,40759$ \\
\hline Micronutriente & & & 0,$87 ; 0,43298$ \\
Cobre $(\mathrm{Cu})$ & $9,00 \pm 1,63$ & $8,75 \pm 1,58$ & $6,63 \pm 0,57$ & 0,$56 ; 0,58210$ \\
Ferro $(\mathrm{Fe})$ & $62,75 \pm 2,58$ & $58,38 \pm 6,46$ & $67,25 \pm 4,40$ & 1,$84 ; 0,18309$ \\
Manganês $(\mathrm{Mn})$ & $8,88 \pm 2,24$ & $7,00 \pm 1,12$ & $6,88 \pm 0,72$ & \\
Zinco $(\mathrm{Zn})$ & $107,13 \pm 2,22$ & $112,13 \pm 1,79$ & $112,38 \pm 2,49$ &
\end{tabular}


Cádmio (Cd)

Chumbo $(\mathrm{Pb})$

Cromo (Cr)

${ }^{(1)} \mathrm{F}$ : Variável do teste, $\mathrm{p}$ : valores críticos

A exigência mínima de $0,5 \%$ de Ca na dieta determinada por Miranda et al. (2000) pode ser observada em todas as dietas no presente estudo em que a disponibilidade deste macro mineral na carcaça varia entre 53,31 e 62,93, respectivamente para os peixes que não consumiam probiótico e $B$. subtilis.

A adição de probióticos na ração $(p>0,05)$ não afetou os micronutrientes essenciais cobre, ferro, manganês e zinco e, os tóxicos cádmio, chumbo e cromo (Tabela 4).

Os teores de $\mathrm{Cu}$ da carcaça dos peixes eviscerados variaram entre 6,63 e $9,00 \mathrm{mg} / \mathrm{kg}$, respectivamente, para Bacillus cereus e ausente de probióticos e, estão dentro do limite máximo permitido da legislação brasileira que é de $30 \mathrm{mg} / \mathrm{kg}$ (Tabela 4).

A legislação brasileira não delimita valores máximos dos metais pesados essenciais $\mathrm{Fe}$ e $\mathrm{Mn}$ em alimentos. Porém, os resultados para estes dois micronutrientes foram menores que os observados por Marengoni et al. (2008) que estudando o desempenho produtivo de linhagens de tilápias mencionaram concentrações máximas de 1.101,50 e $12,50 \mathrm{mg} \mathrm{kg}$ e 445,00 e $5,25 \mathrm{mg} / \mathrm{kg}$ para a variedade GIFT e Chitralada, respectivamente para Fe e Mn.

As amostras das carcaças evisceradas ao final do cultivo apresentaram o dobro da concentração recomendada do metal $\mathrm{Zn}$ em alimentos prevista pela regulamentação que é de 50 $\mathrm{mg} / \mathrm{kg}$ (Tabela 4). Estes resultados são similares aos expressos por Souza et al. (2009) que estudando metais pesados em diversas espécies de um pesqueiro encontraram uma variação entre 19,6 e $145,7 \mathrm{mg} / \mathrm{kg}$ para este metal.

Pode-se observar na Tabela 4, que a concentração média de $\mathrm{Cd}$ para todos os peixes dos grupos submetidos ou não a probióticos na alimentação foi de $1,00 \mathrm{mg} / \mathrm{kg}$, ou seja, o limite máximo estabelecido pela legislação para este metal em alimentos (BRASIL, 1962).

Os metais pesados tóxicos ultrapassaram os valores permitidos delimitados pela legislação, sendo verificados teores máximos para Bacillus subtilis $(8,38$ e $13,63 \mathrm{mg} / \mathrm{kg})$ e para os peixes que não continham probióticos na formulação $(6,25 \mathrm{e}$ $13,00 \mathrm{mg} / \mathrm{kg})$, respectivamente para $\mathrm{Pb}$ e $\mathrm{Cr}(2,00 \mathrm{e}$ $0,1 \mathrm{mg} / \mathrm{kg}$ ). Resultados similares ao referido trabalho para o metal cromo também foram obtidos por Espinoza-Quiñones et al. (2010) que estudando elementos traços em músculos, brânquias e gônadas de peixes do Rio São Francisco do Paraná, obtiveram valores de $0,15 \mathrm{mg} / \mathrm{kg}$, ou seja, superior permitido pela ANVISA (BRASIL, 1965).

Apesar da maioria dos metais pesados do estudo em questão estarem acima do recomendado pela legislação em vigor, estas informações são de extrema importância na avaliação da qualidade dos alimentos produzidos, controle ambiental, no sentido de avaliar a bioacumulação da fauna, flora e qualidade da água e, portanto, minimizarmos os prováveis impactos gerados da ação antrópica sobre o meio ambiente.

Considerando uma melhora na sobrevivência e nenhuma influência negativa sobre os índices corpóreos, composição centesimal, macro e micronutrientes da carcaça dos alevinos de tilápia do Nilo, variedade GIFT, se recomenda a utilização de Bacillus subtilis C-3102 ou Bacillus cereus var. Toyoi.

\section{AGRADECIMENTOS}

Os autores sinceramente agradecem á Coordenação de Aperfeiçoamento de Pessoal de Nível Superior (CAPES), pelo auxílio financeiro concedido durante a pesquisa.

\footnotetext{
ABSTRACT: Probiotics have gained prominence in aquaculture production as growth promoters, especially in tilapia culture, by being able to survive the gastrointestinal tract, adhere intestinal wall cells, reduce or prevent pathogens not be pathogenic to the host. The objective was to evaluate the performance, body indexes and macro and micronutrient composition of the carcass of the Nile tilapia, GIFT variety, fed with diets formulated with probiotic Bacillus cereus var. Toyoi and Bacillus subtilis C-3102, during nursery. There were used 720 post-larvae with initial average weight of $26.6 \pm$ $3.4 \mathrm{mg}$. Fish were randomly distributed in a system of 24 aquaria of $0.03 \mathrm{~m}^{3}$ a completely randomized design consisting of three treatments and eight replications, consisting of two probiotics, and probiotic treatment absent. The data parameters were analyzed by ANOVA at $5 \%$. There were no significant differences $(p>0.05)$ in fish from all treatments for the final weight, weight gain, specific growth rate and feed intake. The final biomass, gain and survival of fish biomass was
} 
affected significantly $(p<0.05)$ by addition of any one of the probiotics in relation to the absent. There were no differences $(p>0.05)$ in body composition and with probiotics or absent in diets. The inclusion of any of probiotics was influenced $(p<0.05)$ on calcium levels in the carcass of fish fingerlings in relation to the missing of probiotics. The use of $B$. subtilis or B.cereus improves performance and does not negatively affect the body indexes, macro and micronutrients in the carcass of Nile tilapia, GIFT variety.

KEYWORDS: Corporal Indexes. Fingerlings. Performance Produtive. Probiotics. Tilapia Culture.

\section{REFERÊNCIAS}

ALBUQUERQUE, Daniele Menezes. Bacillus cereus var. Toyoi e Bacillus subtilis C-3102 em dietas para alevinos de tilápia do Nilo, variedade GIFT. 2011. 38f. Dissertação (Mestrado em Engenharia de Pesca e Recursos Pesqueiros) - Curso de Pós Graduação em Recursos Pesqueiros e Engenharia de Pesca, Universidade Estadual do Oeste do Paraná, Toledo, 2011.

ABD-EL-RHMAN, A. M. M. Antagonism of Aeromonas hydrophila by propolis and its effect on the performance of Nile tilapia, Oreochromis niloticus. Fish \& Shellfish Immunology, v. 27, p. 454-459, 2009. Acesso em: 24 de jan. 2014.

ALY, S. M.; MOHAMED, M. F.; JOHN, G. Effects of probiotics on the survival, growth and challenge infection in tilapia nilotica (Oreochromis niloticus). Aquaculture Research, Oxford, v. 39, p. 647-656, jun. 2008. Acesso em: 24 de jan. 2014.

AOAC. Association of Official Analytcal Chemists. Official methods of analysis. $18^{\text {th }}$ ed. Gaithersburg: Maryland, 2005.

BÁLCAZAR, J. L.; BLAS, I.; RUIZ-ZARZUELA, I.; CUNNINGHAM, D.; VENDRELL, D.; MÚZQUIZ, J. L. The role of probiotics in aquaculture. Veterinary Microbiology, Oxford, v. 114, p. 173-186, maio. 2006. Acesso em: 24 de jan. 2014.

BRASIL. Leis, Decretos, etc. Decreto ${ }^{\circ} 55871$ de março 1965. Modifica o decreto $n^{\circ} 50040$, de 24 janeiro 1961 referente a normas regulamentadoras do emprego de aditivos para alimentos, alterado pelo Decreto $\mathrm{n}^{\circ}$ 691, de 13 de março 1962. Diario Oficial. Brasília, 9 abril 1965. Seç. 1, pt. 1, p.3611.

BRASIL/IBGE. Produção da Pecuária Municipal 2013. Brasília: v.41, 2014. 108p.

CYRINO, J. E.; BICUDO, A. J. A.; SADO, R. Y.; BORGHESI, R.; DAIRIKI, J. K. A piscicultura e o ambiente - o uso de alimentos ambientalmente corretos em piscicultura. Revista Brasileira de Zootecnia, Viçosa, v. 39, p. 68-87, jul. 2010. Acesso em: 24 de jan. 2014.

EL-HAROUN, E. R.; GODA, A. M. A-S; CHOWDHURY, M. A. K. Effect of dietary probiótico Biogen® supplementation as a growth promoter on growth performance and feed utilization of Nile tilapia Oreochromis niloticus (L.). Aquaculture Research, Oxford, v. 37, p. 1473-1480, out. 2006. Acesso em: 24 de jan. 2014.

EL-SAYED, A. F. M.; KAWANNA, M. Optimum water temperature boosts the growth performance of Nile tilapia (Oreochromis niloticus) fry reared in a recycling system. Aquaculture Research, Oxford, v. 39, p. 670672, abr. 2008. Acesso em: 24 de jan. 2014.

ESPINOZA-QUIÑONES, F. R.; MÓDENES, A. N.; PALÁCIO, S. M.; SZYMANSKI, N.; RIZZUTTO, M. A.; BORBA, C. E.; KROUMOV, A. D. Evaluation of trace element levels in muscles, liver and gonad of fish species from São Francisco River of the Paraná Brazilian state by using SR-TXRF technique. Applied Radiation and Isotopes, v. 68, p. 2202-2207, jun. 2010. Acesso em: 24 de jan. 2014. 
FARIAS, A. C. E. A.; HAYASHI, C.; GALDIOLI, E. M.; SOARES, C. M. Farinha de peixe em rações para alevinos de tilápia do Nilo, Oreochromis niloticus (L.), linhagem tailandesa. Acta Scientiarum. Animal Sciences, Maringá, v. 3, p. 903-908, 2001. Acesso em: 24 de jan. 2014.

FAO/WHO. Guidelines for the evaluation of probiotics in food. London Ontario: Food and Agriculture Organization of the United Nations/ World Health Orgnization, 2002. Disponível em:

$<$ http://www.fao.org/es/ESN/food/foodandfood_probio_en.stm>. Acessado em 07 fev. 2002.

HE, S.; ZHANG, Y.; YANG, Y.; MARUBASHI, T.; ZHIGANG, Z.; YAO, B. Effect of dietary Bacillus subtilis $\mathrm{C}-3102$ on the production, intestinal, cytokine expression and autochthonous bacteria of hybrid tilapia Oreochromis niloticus +9 x Oreochromis aureus $\hat{\partial}$. Aquaculture, Amsterdam, v. 412-413, p. 125-130, jul. 2013. Disponível em: < http://www.genedenovo.com/uploads/tmp/genedenovo-resume1386570855.8791475.pdf> Acesso em: 24 de jan. 2014.

HISANO, H.; NARVÁEZ-SOLARTE, W. V.; BARROS, M. M.; PEZZATO, L. E. Desempenho produtivo de alevinos de tilápia-do-nilo alimentados com levedura e derivados. Pesquisa Agropecuária Brasileira, Brasília, v. 42, p. 1035-1042, jul. 2007. http://dx.doi.org/10.1590/S0100-204X2007000700017

KESARCODI-WATSON, A.; KASPAR, H.; LATEGAN, M. J.; GIBSON, L. Probiotics in aquaculture: the need, principles and mechanisms of action and screening processes. Aquaculture, Amsterdam, v. 274, p. 1-14, jan. 2008. http://dx.doi.org/10.1016/j.aquaculture.2007.11.019

LALL, S. P. Mineral Nutrition. In: J. E. Halver and R.W. Hardy (eds.), Fish Nutrition, $3^{\text {rd }}$ ed., Academic Press, USA: San Diego, 2002. p.260-308.

MARENGONI, N. G.; ALBUQUERQUE, D. M.; MOTA, F. L. S.; PASSOS NETO, O. P.; SILVA NETO, A. A.; SILVA, A. I. M.; OGAWA, M. Desempenho produtivo de tilápia vermelha submetida à dieta contendo probiótico durante a alevinagem em água mesohalina. Archivos de Zootecnia, Córdoba, v. 59, p. 403-414, set. 2010.

MARENGONI, N. G.; POSSAMAI, M.; GONÇALVES JÚNIOR, A. C.; OLIVEIRA, A. A. M. Performance e retenção de metais pesados em três linhagens de juvenis de tilápia-do-Nilo em hapas. Acta Scientiarum. Animal Sciences, Maringá, v. 30, n. 3, p. 351-358, 2008.

MARQUES, N. R.; HAYASHI, C.; SOARES, C. M.; SOARES, T. Níveis diários de arraçoamento para alevinos de tilápia do Nilo (Oreochromis Niloticus, L.) cultivados em baixas temperaturas. Semina, Londrina, v. 24, p. 97-104, jan/dez. 2003.

MELLO, H.; MORAES, J. E.; NIZA, I. G.; MORAES, F. R.; OZÓRIO, R. O. A.; SHIMADA, M. T.; ENGRACIA FILHO, J. R.; CLAUDINO, G. S. Efeitos benéficos de probióticos no intestino de juvenis de Tilápia-do-Nilo. Pesquisa Veterinária Brasileira, Rio de Janeiro, v. 33, n. 6, p. 724-730, jun. 2013

MIRANDA, E. C.; PEZZATO, A. C.; PEZZATO, L. E.; GRANER, C. F.; ROSA, G. J.; PINTO, L. G. Q. Relação Cálcio/Fósforo disponível em rações para tilápia do Nilo (Oreochromis niloticus). Revista Brasileira de Zootecnia, Viçosa, v. 29, n. 9, p. 2162-2171, 2000.

MOURA, G. S.; OLIVEIRA, M. G. A.; LANNA, E. T. A.; MACIEL JÚNIOR, A.; MACIEL, C. M. R. R. Desempenho e atividade de amilase em tilápias-do-nilo submetidas a diferentes temperaturas. Pesquisa Agropecuária Brasileira, Brasília, v. 42, p. 1609-1615, nov. 2007. http://dx.doi.org/10.1590/S0100204X2007001100013

NAYAK, S. K. Probiotics and immunity: A fish perspective. Fish \& Shellfish Immunology, v. 29, p. 2-14, fev. 2010. http://dx.doi.org/10.1016/j.fsi.2010.02.017 
OGAWA, M. Química do pescado. In: OGAWA, M.; MAIA, E. L. Manual de pesca. São Paulo: Livraria Varela, 1999. p. 29-72.

PEZZATO, L. E.; MIRANDA, E. C.; BARROS, M. M.; PINTO, L. G. Q.; FURUYA, W. M.; PEZZATO, A. C. Digestibilidade aparente de ingredientes pela tilápia do Nilo (Oreochromis niloticus). Revista Brasileira de Zootecnia, Viçosa, v. 31, p. 1595-1604, 2002.

SAHU, M. K.; SWARNAKUMAR, N. S.; SIVAKUMAR, K.; THANGARADJOU, T.; KANNAN, L. Probiotics in aquaculture: importance and future perspectives. Indian Journal Microbiology, v. 48, p. 299308, set. 2008. http://dx.doi.org/10.1007/s12088-008-0024-3

SOUZA, G. R.; GARCEZ, M. A. P.; SANTOS, V. C. G.; SILVA, D. B.; CAETANO, J.; DRAGUNSKI, D. C. Quantificação de metais pesados em peixes de um pesqueiro localizado na cidade de Umuarama. Arquivos de Ciências Veterinárias e Zoologia da Unipar, Umuarama, v. 12, n. 1, p. 61-66, jan/jun, 2009.

TACHIBANA, L.; DIAS, D. C.; ISHIKAWA, C. M.; CORREA, C. F.; LEONARDO, A. F. G.; RAZANIPAIVA, M. J. T. Probiótico na alimentação da tilápia-do-Nilo (Oreochromis niloticus Linnaeus, 1758), durante a inversão sexual: desempenho zootécnico e recuperação da bactéria probiótica intestinal. Bioikos, Campinas, v. 25, n. 1, p. 25-31, 2011. Acesso em: 24 de jan. 2014.

TEDESCO, M. J.; GIANELLO, C.; BISSANI, C. A.; BOHNEN, H.; VOLKWEISS, S J. Análises de Solo, Plantas e Outros Materiais. 2. ed. Porto Alegre: Universidade Federal do Rio Grande do Sul, 1995. 174p. (Boletim técnico, 5).

TIMMERMAN, H. M.; KONING, C. J. M.; MULDER, L.; ROMBOUTS, F. M.; BEYNEM, A. C. Monostrain, multistrain and multispecies probiotics - A comparison of functionality and efficacy. International Journal of Food Microbiology, Grugliasco, v. 96, p. 219-233, maio. 2004.

VAZOLLER, A. E. A. M. Biologia da reprodução de peixes teleósteos: teoria e prática. Maringá: EDUEM, 1996. 169p.

WELZ, B.; SPERLING, M. Atomic absorption spectrometry. Weinheim: $2^{\text {th }}$.ed., Weinheim: Wiley-VCH, 1999. $411 \mathrm{p}$.

WILLIAM, L. D.; BURDOCK, G. A.; JIMÉNEZ, G.; CASTILLO, M. Literature review on the safety of Toyocerin $^{\circledR}$, a non-toxigenic and non-pathogenic Bacillus cereus var. Toyoi preparation. Regulatory Toxicology and Pharmacology, San Diego, v. 55, p. 236-246, jul. 2009.

http://dx.doi.org/10.1016/j.yrtph.2009.07.009 